\title{
Book Review Symposium
}

\author{
Karen M. Johnson-Weiner. The Lives of Amish Women. Baltimore: Johns Hopkins \\ University Press, 2020. Pp. 320.
}

Published October 8, 2021

https://doi.org/10.18061/jpac.v2i1.8294

$\mathrm{n}$ this symposium, three readers respond to Karen M. Johnson-Weiner's book, The Lives of
Amish Women, published in fall 2020 by Johns Hopkins University Press. We offer their reviews below, in alphabetical order.

Reviewer Marlene Epp is Professor of History and Peace and Conflict Studies at Conrad Grebel University College, in Waterloo, Ontario, and the author of Mennonite Women in Canada: A History (University of Manitoba Press, 2008). Lucinda J. Kinsinger is a writer living in Oakland, Maryland, and a member of the Amish-Mennonite Church there. She is the author of Anything but Simple: My Life as a Mennonite (Herald Press, 2017). Jill E. Korbin is Lucy Adams Leffingwell Professor of Anthropology at Case Western Reserve University, in Cleveland, Ohio, and the author of numerous articles on Amish society, especially with regard to matters of health and well-being.

A response from Karen Johnson-Weiner, Distinguished Service Professor of Anthropology Emerita at the State University of New York-Potsdam, Potsdam, New York, follows the reviews.

Marlene Epp, Professor of History and Peace and Conflict Studies, Conrad Grebel University College, University of Waterloo, Waterloo, Ontario

The Amish, like many traditionalist Anabaptist groups, tend to be either idealized or vilified by media and the general public, as well as by scholars. Portrayals of Amish women sometimes hold these polarizations together, whereby women are depicted as wholesome, quaint, and yet oppressed. In any case, the Amish, both men and women, are often stereotyped in simplistic ways according to an onlooker's preconceived notions. In this welcome overview of Amish women, Karen M. Johnson-Weiner portrays a community that is much more complex than frequently depicted, a community in which women's roles have a certain core sameness yet diverge across groups according to their degree of integration into modern society.

While this is explicitly a book about women, it is also a study of gender more broadly, as the lives of boys and men play a prominent role. Indeed, the Amish exhibit a fascinating and intentional ordering of their society around gender norms and expectations, a foundational reality lacking in literature on this group. Deeply gendered rituals such as physically preparing a household to host church, or a pig-butchering "frolic," described precisely and vividly by the author, reveal clearly delineated roles. In many respects, the maintenance of the "Amish way" depends on spoken and silent customs of gendered behavior. Responding to the onlooker's 
perception of a society in which males dominate, Johnson-Weiner embeds her gender analysis in a framework of "soft patriarchy" that demands mutual submission of women and men.

This book is also a useful resource on the everyday lives of the Amish overall-not surprising given the author's long-term expertise on this Plain community. Some chapters focus directly on girls and women, while others wander into wider aspects of Amish custom. The chapter themes are organized partly by life cycle — girlhood, marriage, mothering, and singleness - and partly by the domestic labor, daily activities, seasonal events, and other habits that bring women together. The fact that individual women are not prominent in the narrative points to the centrality of family and community for the Amish. Johnson-Weiner organizes her analysis around a "community of practice" concept, whereby each stage and activity of an Amish woman's life is about learning the "tools, stories, and values" (x) required to make her a full participant in the community. As they practice and perform being Amish, girls and, later, women are differentiated from one another according to the varied and evolving nature of their particular Amish community and the boundaries set between themselves and the non-Amish world.

The divergence from homogeneity is discussed clearly in Chapter 7, "Reading Amish Women," which is my favorite section of the book. Given the notion of the Amish as producers and reproducers, and always at work, reading does not often come to mind as a common, or even acceptable, activity. In this chapter, the author analyses three magazine-type publications preferred by three types of Amish women. Among the "agrarian" Amish, the most traditional, both women and men have clearly defined roles that are mutually dependent in a farming household. In this context - the example of Swartzentruber Amish is used the most-women have "much greater responsibility for the spiritual, economic, and social health of the church community" (25). A certain "separate but equal" scenario exists here.

In what Johnson-Weiner calls "entrepreneurial" Amish communities, women depart from tradition by operating home-based businesses that compel them to interact with the mainstream and that provide some economic power, even while they do not depart from their primary domestic activity. From there, women in "wage-labor" communities depend on the income earned by their menfolk while they perform their roles as wives and mothers. While the latter are most "progressive" (a value-laden label I consider unhelpful in a study on gender) in terms of their modernist integration, their embrace of evangelical Christianity's patriarchal gender norms render these women more confined and less powerful than their so-called conservative agrarian sisters. Without a clear economic role to play, a primary responsibility of women in this grouping is to ensure their menfolk remain secure in the community's traditional religious values. The author's organization of Amish women according to economic categories is an astute, if surprising, approach to categorizing a religious body.

This book is a significant contribution to the literature on gender within Plain communities, indeed to the overall culture of those groups. I enjoyed reading it immensely. There are a few topics and interpretative angles that I think could have been developed more incisively.

As a historian, I would have liked the study to be put in context to a greater extent. JohnsonWeiner begins with a discussion of the sixteenth-century antecedents of contemporary Amish 
women, surveys some internal church divisions and shifts, and near the end concludes that Amish understandings of womanhood are "shaped by historical events" (240), yet I was surprised by the largely ahistorical treatment of the subject over time. Even while there is a certain timelessness to Amish ways, especially in the household, Plain communities do evolve in reaction to change and continuity in mainstream society. Several waves of feminism over the course of the twentieth century, dramatic transformations in household technology, and the growth of evangelical Christianity are among the movements that had significant impact on the roles and understandings of women; even separatist societies were not immune from these transformations.

One important example of this, very central to Amish women's lives, are changes to childbirth and birth control. For communities with above average family sizes, pregnancy (and the avoidance or termination thereof) and childbirth are frequent events in the lives of most Amish women. I would have liked to know about the historic presence of midwife-healers among the Amish and the medicalization of childbirth, as well as changes (or possibly lack of change) to fertility control. This surely functions as a key preoccupation of adult Amish women past and present. JohnsonWeiner does note the difficulty of obtaining information and opinions about this private aspect of women's lives, but is largely uncritical toward the lack of knowledge on reproduction; even gaps merit deeper interpretation. Increasingly popular theoretical frameworks about gender and "the body" could be helpful here, especially given that Amish woman are often described according to their physicality.

Conflict is another topic addressed minimally, whether between men and women, within households, or as inner conflict for women who exist with limited choices for their lives. Corporal punishment of children, for example, is addressed in one paragraph. Importantly, Johnson-Weiner has a short section on abuse, acknowledging the existence of violence in Amish households, yet says little about what the church's response to such situations is. Numerous scholars have made linkages between domestic violence and patriarchal societies in which female submission is a key religious mandate. If such a cause and effect does not exist among the Amish, then we need a deeper analysis of how "mutual submission" functions in practice. Other explorations of gender in Anabaptist groups suggest that women carry a double dose of submission and self-denial, in light of that religion's signature emphasis on Gelassenheit (yieldedness), humility, and service to others - traits that are gendered female in society generally. The tragic West Nickel Mines schoolhouse shooting of ten Amish girls in 2006 has been the subject of attention of many kinds, but little gender analysis. Although the perpetrator was not Amish, the impact of this among Amish must surely have had some gender dimensions in terms of how the tragedy was processed and why females were the targets. Amish forgiveness is the focus here, but forgiveness as a value and an action needs to be gendered. It is exactly because the Amish hold nonresistance as a religious belief that the presence of conflict, especially violence, needs to be addressed deeply.

This is a study of Amish women's lives by an outsider, yet someone who knows the community well and so can offer detailed description of discrete, yet highly important, rituals and customs. As such, the reader is offered a sometimes bewildering, consistently compelling, and often delightful glimpse into the practices, patterns, and performances of girls and women learning to be Amish. 


\section{Lucinda J. Kinsinger, Oakland, Maryland}

I did not grow up in an Amish community and know almost nothing of the difference between Swartzentruber, Old Order, Andy Weaver, and Troyer affiliations. As the daughter of a conservative Mennonite pastor, I can most easily differentiate the Plain groups that carry names like Nationwide, Bethel, and Midwest. However, the ideas and lifestyles presented by Karen Johnson-Weiner in The Lives of Amish Women are not completely foreign to me.

I grew up reading Family Life, Keepers at Home, and Pathway readers, Amish publications Johnson-Weiner mentions. My dad's grandparents came from the Amish, and I heard him speak Pennsylvania Deitsch frequently to his mom. I barely realized then that phrases like "It wonders me," which had worked themselves into my dad's everyday language, were Deitsch. Church decisions in my home community, as in Amish faith practices, were "shaped both by a desire to keep the church pure and by a suspicion of society outside the bounds of the church community" (13).

More recently, since my marriage, I have grown to know and love the New Order Amish community in Oakland, Maryland. I have tasted the traditional Amish meal-served in this community only occasionally — of bean soup, schnitz pies, red beets, and pickles. I have made my own observations on the differences between Amish and conservative Mennonite culture. One of these days I may speak Pennsylvania Deitsch as well as Johnson-Weiner herself does.

Johnson-Weiner writes that her first goal for The Lives of Amish Women "is to describe the lives led by women in different types of Amish communities," to "draw on their own words and their stories" (xii). With my small knowledge of Amish communities, I cannot tell how accurately she has achieved her goal. Johnson-Weiner herself acknowledges the difficulty of the task: "In writing about Amish women, one faces the difficulty of trying to define who they are, when the reality is that they are diverse" (231).

I, for one, trust an expert who acknowledges diversity far more than one who seems unaware of it. I have long disliked Amish romances for their glossy, stock-photo images of Amish life. Do English authors really imagine they portray an accurate picture of the culture? I mean! The young women on the covers wear lipstick and pluck their eyebrows, for crying out loud. (Imagine my surprise to learn that the Amish ladies Johnson-Weiner knows enjoy the novels I had thought culturally appropriative.) Regardless, I appreciate Johnson-Weiner's own nuanced perspective, her refusal to class all Amish into one glorious lump.

An author will find pitfalls, though, when delving into such a multiplicity of lives. In her chapter titled "Reading Amish Women," Johnson-Weiner cites three contributors to Keepers at Home magazine: Sheila Petre, Gina Martin, and Stephanie Leinbach, all of whom I know personally. These ladies are not Amish, but conservative Mennonite, and all of them were annoyed at the way Johnson-Weiner misconstrued their words to underscore her points. She made them sound overly submissive, overly sanctimonious, they believed. She cherry-picked quotes and failed to accurately reflect their meanings. "If I were to seek out information on Amish women, I 
would not pick up this book," Leinbach told me. "I don't trust the author to represent them accurately. She didn't represent me accurately."

Though Johnson-Weiner may have misrepresented individual authors, perhaps she got the essentials right. Amy Engbretson, another friend of mine who happens to be a daughter of the Keepers at Home publishers, felt that Johnson-Weiner was "remarkably astute" in how she differentiated between Keepers at Home and another Amish publication, Ladies Journal.

Engbretson, who grew up New Order Amish, wrote that The Lives of Amish Women was "hilariously inaccurate as far as the details of my own experience as an Amish woman." But she acknowledged that Johnson-Weiner focused on Swartzentruber and Old Order Amish groups, not New Order Amish. Despite the dissimilarities between her own lifestyle and those women written about, Engbretson "saw a lot of ideas mentioned that I grew up with, not overtly taught as much, but part of the air, you might say."

Johnson-Weiner excels at picking out subtle differences between cultures. For example, she discusses how the agrarian lifestyle of Swartzentruber Amish women brings them a greater sense of equality with their husbands than is experienced by more progressive Amish women. Women in agrarian cultures labor side by side with their husbands in both the fields and the kitchen. Women in more progressive cultures often stay home and labor alone while their husbands become the sole breadwinners, creating a sharp divide in gender roles and a greater sense of dependency in the wife.

Amish women and men both play defined roles in a defined community. Women are mothers, farmer's wives, schoolteachers, shopkeepers. Men are fathers, farmers, preachers, construction workers. Few Amish hold office jobs or continue their formal education beyond eighth grade. While the men hold positions of authority in homes and churches, Johnson-Weiner calls their form of patriarchy "soft patriarchy," mollified by their gentle, Gelassenheit-influenced faith. From my own experience in Plain communities, I would call that an accurate description.

Johnson-Weiner gave me new things to think about. "The Amish have a lived faith," she writes (23). Growing up, I learned that one must have an inner experience with God, be born again, to be a true Christian. Johnson-Weiner, however, paints a picture of a people who learn their faith by doing and who live out their faith within community. Like Mennonites, only more so, perhaps comparable to the rural oral faiths of the Middle Ages. Between the community-controlled Christianity of the Amish and the hyper-individualized Christianity of modern America, who am I to say that the "personal relationship" model has got it right? The Bible tells us Christ's body is not an individual, but the Church.

"Ideally, the stories and analysis in the pages that follow will foster greater appreciation and understanding of all the varied ways in which Amish women construct rich identities" (xii), Johnson-Weiner writes. For me, The Lives of Amish Women has fostered that appreciation. 
Jill E. Korbin, Lucy Adams Leffingwell Professor of Anthropology, Schubert Center for Child Studies, Case Western Reserve University, Cleveland, Ohio

Karen Johnson-Weiner foreshadows the scope of her impressive ethnography, The Lives of Amish Women, in her preface, by saying, "the land of Amish women is not easily traveled" (vii). JohnsonWeiner, Distinguished Service Professor of Anthropology Emerita at the State University of New York, Potsdam, then goes on to take the reader on a fascinating and enlightening journey, immersing us in the ways that Amish women live and experience their lives.

In this volume, Johnson-Weiner builds on her impressive, decades-long scholarship on Amish persons and communities, directing her attention to the too-easily-stereotyped, unidimensional Amish woman, dressed as she is in clothing in the fashion from earlier centuries, driving a horse and buggy, and eschewing modern conveniences as she raises children, cooks healthy and delicious meals, and keeps a clean and orderly home. Johnson-Weiner disabuses us of this tooeasy stereotype by showing the diversity and multifaceted nature of Amish women and their families.

The methodology employed by Johnson-Weiner is participant observation, the hallmark of anthropological research in which one learns about others (sometimes referred to as "The Other") by engaging with them in their daily lives. In a community well-known for being closed, insular, and by design disinclined to engage with outside influences, Johnson-Weiner invested the time and care necessary to gain the trust of Amish women and their families, enabling her to engage in both the culturally-based traditions, such as weddings and funerals, and the daily routines of washing dishes and caring for young children. It is this kind of immersion that afforded her the perspective on Amish women that she shares with us as her readers.

To take us on this journey towards understanding Amish women, Johnson-Weiner draws on scholarship ranging from historical records from the sixteenth century about the Anabaptist movement and the severe persecution that did not spare women, to anthropological and sociological work on culture and gender, to publications aimed at and contributed to by Amish people such as Family Life, to existing scholarship on Amish communities, including her own. Johnson-Weiner has an impressive record of publication about Amish people - for example, Train Up a Child: Old Order Amish and Mennonite Schools (2007), New York Amish: Life in the Plain Communities of the Empire State, second edition (2017), and a comprehensive book about the Amish coauthored with Donald Kraybill and Steven Nolt, The Amish (2013). All of these sources are blended seamlessly with her experiences in interactions with Amish women and their families.

Building on a foundational chapter on the history of the Anabaptist Movement and the role of women in that religious tradition, the chapters of The Lives of Amish Women guide us through the life course experiences of Amish women from infancy to old age. In addition to explaining these various stages of life, Johnson-Weiner considers categories of Amish women who depart, through no fault of their own, from the usual and accepted roles. These include unmarried women ("single girls," despite their age), widows, and LGBTQ individuals. While to differing extents Amish communities accept, care for, and integrate these women, their life courses nonetheless depart from expectations. The extent of this integration is somewhat different for unmarried and widowed 
women versus lesbian women, who violate religious beliefs against homosexuality and generally remain unidentified as such.

A significant strength of this book is its attention to diversity among Amish women. JohnsonWeiner grounds the diversity of Amish women's lives along three pathways delineated largely by economic parameters. These three pathways are agrarian small farms, entrepreneurial endeavors (small shops to larger businesses), and wage labor. In this way, she distinguishes among Amish women and the ramifications of these pathways for their daily lives, families, and child-rearing. If, for example, the father is away from the home engaging in wage labor at a factory, then more of the child-rearing falls to the wife and there is less opportunity for fathers to engage and teach their youngsters to prepare them for their future roles. Similarly, an Amish woman with a small business or shop must manage both the work responsibilities that provide income as well as the responsibilities for raising her children and maintaining a smoothly running home.

Among the many contributions of the book, Johnson-Weiner addresses head-on the thorny and complicated issue of patriarchy, offering in-depth and nuanced explanations of what she terms "soft patriarchy." Johnson-Weiner leads the reader through the extraordinary level of cooperation that is required of an Amish couple and the historical and contemporary centrality of women as true partners in marriage and the family. As she skillfully explains, stemming from the early days of Anabaptist thought, Amish women are equal to men as church members, even if they do not hold positions of authority (bishop, preacher, deacon) in their church districts. Bishops in the church and husbands and fathers in the family have the final authority, but it does not emerge out of coercion but out of cooperation and collaboration. Gelassenheit, or acceptance, is the guiding principle in which women (and men) see themselves as embedded in a community with individual good firmly rooted in the collective good. Married couples, as Johnson-Weiner documents with examples, must work together, living according to church doctrines for their own and group wellbeing.

Johnson-Weiner also draws our attention to the power of reading materials among the Amish. She points to publications like Family Life to show how Amish women (and men) use the printed word to express their values and seek help from one another on a range of topics. This is despite Amish children only attending school through the eighth grade, a fact that may make outsiders skeptical about Amish use of the written word.

Johnson-Weiner also conveys the profound heartbreak when a woman's children leave the Amish community. While families and communities have a range of responses to these situations, it is an enormous wound both to the parents and the larger community. On one occasion, I told an Amish woman that an analysis of community data had shown that a very high percentage of youth in her community joined church, thus remaining Amish. She responded with distress about the small percentage of young people who left the church, underlining the importance of every individual to the community of believers. In mulling this over, it seemed that it would be as if I had been told not to worry that only a small percentage of college-age children (like my own then) would get a rare disease and die. 
Constructive critiques of this book are along the lines of asking for more while recognizing that any single volume is limited in what it can include. I would like to know more from JohnsonWeiner, for example, about the individual variability among Amish women within the three pathways she identifies. I would like to know more of her thoughts about those Amish women who work in non-Amish homes, often for years with the same families. In short, I hope to hear more from her in subsequent books.

Johnson-Weiner has created a highly readable and engaging book that I found thoroughly enjoyable. I appreciate the opportunity to review it and recommend it to both those in academics and the general public.

\section{Karen M. Johnson-Weiner responds:}

I want to thank Marlene Epp, Lucinda Kinsinger, and Jill Korbin for taking the time to read and critique The Lives of Amish Women. I am grateful for their insights and honored by their attention to my work.

I did not find it easy to write about Amish women, and once I began writing, I was not sure at all where I would end up. There was simply so much to say. I found the task made more challenging by the diverse nature of the Amish world. The more I explored, the more I discovered that the commonalities in the Amish world masked diverse meanings and understandings of Amish life. Moreover, researching Amish church-communities as communities of practice, in which children work with older family and community members to learn how to be and act appropriately as adults, I grew increasingly aware that the faith of the Amish was not lived in the same way by all Amish. As I write in the introduction, "even as the language they use to talk about themselves and their faith may be the same, the meanings may not be" (ix). Studying the lives of Amish women led me to explore how Amish gender has evolved and continues to evolve in the context of historical, economic, social, and religious change. I have come to appreciate how Amish women negotiate a gender identity appropriate to their particular church-community and how that gender identity will become increasingly complex as those church-communities evolve.

Both Epp and Korbin note important issues that are given less coverage than they deserve. Korbin notes, for example, that I generalize within the three broad "paths" of Amish I describe (agrarian, entrepreneurial, wage-labor) and wishes to know more about individual variation. She wonders, in particular, about women who work in non-Amish homes, often for years for the same families. I met women like that (sometimes through their English friends), and their voices informed this study, but, sadly, this individual variation was lost in making the broader point. Each one of the many women I spoke with and whose voices appear in this book is worthy of her own chapter, and I am sorry that I could not do that. In addition, the broader topic of Amish friendships in the non-Amish world deserves study. From the time when the treuherzige (true-hearted) helped Anabaptists hide from persecution to the help provided in the twentieth and twenty-first centuries by worldly lawyers, health care professionals, and others, the Amish have benefited from worldly friendships, and these are worthy of an in-depth exploration that was beyond the scope of this book. 
Epp would have liked greater historical context, and I agree. I was frustrated by my inability to discover more about women and their response to migration and schism. As others have noted, women have been too often written out of the history. Epp also points out that I did not go into depth about Amish midwives or social changes affecting childbirth, particularly birth control, which are certainly of importance to Amish women. Amish life is shaped by the response of church-communities to worldly social forces, and, as I gave women rides to the unlicensed Mennonite midwife, I knew that I was privileged to be entrusted with knowledge of her not-quitelegal practice. Because of the diversity of Amish birthing practices, including home births with unlicensed midwives, the researcher intent on such a broad study faces the difficult task of establishing trust within diverse communities and of communicating with women about topics that many will not discuss in front of children or other unmarried individuals.

James A. Cates's recent work, Serpent in the Garden: Amish Sexuality in a Changing World, is a first-of-its-kind introduction to Amish sexuality and covers in much greater depth some of the issues given only a brief mention in The Lives of Amish Women, including homosexuality and sexual abuse. Further studies of Amish women should focus not only on pregnancy, sex education, and birth control, but also on the general role of Amish women in health care. For example, I hope for a study of women healers and the women who package and sell health supplements. In the book, I mentioned a woman in a very conservative farming community who makes dentures. I discovered her business by accident, and I wish I had had more opportunity to explore how widespread such health care supports are.

As Epp notes, there is also a need for more study of conflict, not only between men and women or within households, but also the inner conflict of women "who exist with limited choices for their lives." This is also true, but we need to be careful in addressing what we outsiders may see as "limited" choices and in assuming that those faced with such choices experience the same inner conflict about them as would those of us raised in a different religious and social context. As I tried to show in my analysis of the magazines, for example, embracing a scripturally-defined role as stay-at-home wives and mothers and accepting the need for a particular kind of submission gives some Amish women a power quite different from the economic power of their agrarian and entrepreneurial counterparts. Although their options appear quite limited, by accepting what they believe God has ordained for them, women gain status and play a valued role in their churchcommunity.

Therefore, I agree wholeheartedly with Epp that "submission" in the Amish world warrants much more study. Numerous studies of the Amish have talked about the importance of submission, but, as I hope I have shown in The Lives of Amish Women, submission means different things to different Amish. Further exploration of the multiple meanings of submission across the spectrum of Amish life would inform a much deeper understanding of the choices made by church members, male and female, and the conflicts inherent in, or resulting from, those choices. Further, as Epp suggests, study of submission and Gelassenheit would also contribute much to a better understanding of the "linkages between domestic violence and patriarchal societies in which female submission is a key religious mandate." Finally, as Epp points out, exploring the multiple 
meanings of submission would bring us to a better understanding of forgiveness in the Amish world.

There are other topics hinted at in this book that also warrant a closer, more in-depth look. For example, how is the role of Ordnung changing across the spectrum of Amish communities and how is this change gendered? In short, I hope that The Lives of Amish Women encourages continued research of Amish women's lives. There is so much more to discover.

Finally, as Kinsinger makes clear, this is a book about horse-and-buggy, Deitsch-speaking Amish women, not their car-driving Beachy Amish sisters nor their Old Order or Conservative Mennonite cousins. Over the years I have often stayed with Old Order Mennonite friends and interacted with their friends, neighbors, and relatives of varying Old Order and Conservative Mennonite affiliations. I have been struck by the differences between various Plain Mennonite churches and between Plain Mennonites and Amish, even those within close geographical contact. Two Old Order Mennonite (Groffdale Conference or "Wenger" Mennonite) women accompanied me on several of my visits to Amish women in Lancaster County, and the differences they pointed out between their lives and those of their Amish neighbors led to numerous discussions of different aspects of Plain life and made it quite clear that simply because one is Plain does not mean one will be familiar with all Plain people.

I found it challenging to write about the diverse world of Amish women; I would have been overwhelmed by a project that attempted to detail the lives of all Plain women. This underscores the need for an exploration of the lives of Old Order and Conservative Mennonite women and the diverse ways in which they too wrestle with the challenges of negotiating rich gender identities in a changing world.

Again, thank you Dr. Epp, Mrs. Kinsinger, and Dr. Korbin. 